\title{
Alterations in Antioxidant Status and Biochemical Indices Following Administration of Dihydroartemisinin-Piperaquine Phosphate (P-ALAXIN ${ }^{\circledR}$ )
}

\author{
E. T. Olayinka and A.Ore \\ Biochemistry Unit, Department of Chemical Sciences, PMB 1066, Ajayi Crowther University, Oyo, Nigeria.
}

\begin{abstract}
Dihydroartemisinin-piperaquine phosphate $\left(P\right.$-ALAXIN $\left.{ }^{\circledR}\right)$ is a fixed-dose artemisinin-based combination therapy (ACT). Despite the efficacy and tolerability of this drug, there are adverse effects associated with it. This study was designed to investigate potential toxicity of two different doses of the drug in rats.Thirty rats (Wistar strain) weighing 200 $\pm 20 \mathrm{~g}$ were completely randomised into three treatment groups; Group A (control), Group B (Therapeutic dose) and Group C (double therapeutic dose of P-ALAXIN ${ }^{\circledR}$ ). Creatinine, Urea and Bilirubin levels were significantly $(p<0.05)$ elevated in the plasma of the rats that received the two doses of P-ALAXIN ${ }^{\circledR}$ by 67 and 117\%; 33 and 67\%; 85 and $119 \%$ respectively when compared to the control. Activities of plasma ALP, ALT, AST and GGT were also significantly ( $p<0.05)$ higher in the two treated group by 22 and 32\%; 26and 36\%; 18 and 34\%; 43 and $91 \%$ respectively. Moreover, plasma Total cholesterol, HDL-cholesterol, LDL-cholesterol and triglycerides in the two treated groups were significantly increase $(p<0.05)$ by 24 and $38 \% ; 38$ and $75 \% ; 37$ and $88 \%$ and 28 and $64 \%$ respectively. These were accompanied by a significant $(p<0.05)$ increase in the MDA level by 33 and $45 \%$ respectively in the two treated groups. Furthermore, the two doses of P-ALAXIN ${ }^{\circledR}$ significantly $(p<0.05)$ reduced hepatic ascorbic acid and GSH by 44 and 58\% and 44 and 75\% respectively, with a concomitant reduction in activities of hepatic GST. Similarly, there was a significant reduction in the activities of hepatic Catalase, and SOD. These data indicate that therapeutic and double therapeutic doses of P-ALAXIN ${ }^{\circledR}$ has adverse effects on both enzymic and non-enzymic antioxidant status and induces marked renal and liver damages and oxidative stress in rats.
\end{abstract}

Keywords:Dihydroartemisinin-piperaquine phosphate,Therapeutic and Double therapeutic doses, Oxidative stress Renal and Liver damage.

\section{Introduction}

Malaria is a vector-borne infectious disease caused by different strains of the protozoan parasites of the genus Plasmodium. The incidence of malaria worldwide is estimated to be 300-500 million clinical cases each year with about $90 \%$ of these occurring in Africa, south of the sahara-mostly caused by $p$. falciparum[1].Effective treatment of malaria has been a great challenge due to the development of resistance of parasite especially P. falciparum to most antimalarial agents. [2] Emphasis on malaria treatment has therefore shifted from the inexpensive, effective and orally administered chloroquine to artemisinin and its derivatives [3].

The artemisinins are highly efficacious against multi-drug resistant $P$. falciparum and capable of producing up to 10,000 fold reductions in parasite biomass per asexual cycle $[4,5]$. However, it has been reported that due to treatment failures associated with monotherapy and artemisinins, combined therapy of artemisinin with other antimalarial agents known as the artemisinin-based combination treatments (ACTs) have been recommended[6, 7, 8].

Artemisinin has a very different mode of action from conventional antimalarial and this makes it particularly useful in the treatment of resistant infections [9].The combinations of Artemisinin derivatives having a short half-life with another drug with a longer duration of action provides a synergistic activity leading to elimination of remaining parasites[10].

The most widely used artemisinin derivatives are artesunate, artemether and dihydroartemisinin (DHA). Based on available safety and efficacy data, different therapeutic options of artemisinin-based combination treatments (ACTs) are now available which include: Artemether-lumefantrine; Artesunateamodiaquine; Artesunate-Sulfadoxine/Pyrimethamine; Artesunate-Mefloquine; Dihydroartemisinin-piperaquine phosphate etc. [11].

Dihydroartemisinin and piperaquine phosphate combination under the trade name P-ALAXIN ${ }^{\circledR}$ is a film coated tablet containing $40 \mathrm{mg}$ of Dihydroartemisinin (DHA) and $320 \mathrm{mg}$ of piperaquine phosphate (PQP). The drug combination is known to be effective against $P$. vivax, $P$. malariae and the multi-resistant $P$. falciparum malaria parasites. DHA is the active metabolite of artemisinin and its derivatives (Fig.1a).These derivatives have more potent blood schizonticidal activity than the parent compound. DHA is the most potent antimalarial of this group of compounds but it is also the least stable. Oral dihydroartemisinin is rapidly absorbed and has a short 
elimination half-life, although little is known of its metabolism [12].DHA mainly interferes with protein and nucleic acid synthesis and with the membrane structures of the food vacuole, nucleus, mitochondria, and endoplasmic reticulum leading to the dissociation of ribosomes from ER and the autophagosis of parasite[13].

Piperaquine phosphate (Fig. 1b), a bisquinoline, structurally related to chloroquine has been shown to exhibit cardiovascular toxicity in overdose with significant electrophysiological effects on the ear [14]. PQP is widely distributed in the liver, kidneys, lungs and spleen. The high lipophilicity of piperaquine results in an extremely high distribution into parasite lipid membranes[15].PQP interferes with the food vacuole membrane of the trophozoites leading to autophagosis of the parasite. Elimination of PQP is very slow with a half -life of about 9 days. The structural determinant of the activity of artemisinins is the endoperoxide bridge which is a specific feature of this type of compounds. It has been suggested that the parasiticidal activity starts with the reaction of artemisinins with haem iron, leading to the generation of activated oxygen species, such as oxygen radicals, or of a C-centred radical of artemisinin itself [16].

Nosten and White [5], had reported that if there is any toxicity observed in artemisinin combination treatments, it may be due to the non-artemisinin component as artemisinin derivatives alone may have relatively low toxicological effects. However, studies with animal had shown that artemisinin and its analogues cause acute hepatotoxicity in guinea-pigs[17] and have adverse effects on biochemical parameters in rabbits [18]. These result in the production of oxygen free radicals and peroxide formation which will lead to the deleterious effects of these agents $[19,20]$. Despite decades of clinical use, there are limited published non-clinical in vivo and in vitro information of Dihydroartemisinin-Piperaquine Phosphate addressing pharmacokinetics, metabolism or toxicity [21]. Therefore, the present study was designed to investigate the effect of administration of different doses of Dihydroartemisinin-Piperaquine Phosphate $\left(\mathrm{P}-\mathrm{ALAXIN}^{\circledR}\right)$ on the antioxidant status and some biochemical indices in rats.

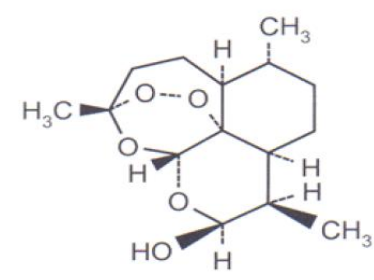

(a) Dihydroartemisinin

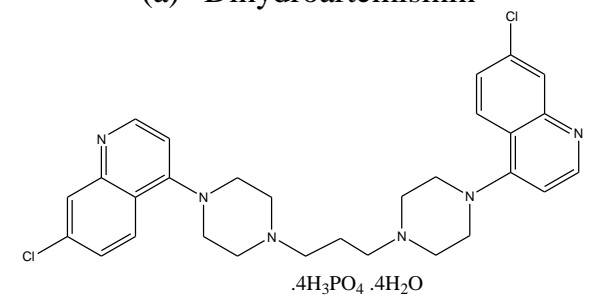

(b) Piperaquine phosphate

Fig 1: Structures of Dihydroartemisinin (DHA) and Piperaquine phosphate (PQP)

\subsection{Chemicals and Reagents}

\section{Materials And Methods}

P-ALAXIN ${ }^{\circledR}$-Dihydroartemisinin plus Piperaquine Phosphate $(360 \mathrm{mg})$, was a product of BLISS GVS Pharmaceutical limited, India. Glutathione (GSH), 1-chloro-2, 4-dinitrobenzene (CDNB), 5,5'-dithio-bis-2nitrobenzoic acid (DTNB), thiobarbituric acid (TBA), epinephrine and hydrogen peroxide were purchased from Sigma chemical company (London, UK). Alanine transaminase (ALT), Aspartate transferase (AST), gamma glutamyl transferase (GGT), urea, creatinine, bilirubin, total cholesterol, HDL - cholesterol, LDL - cholesterol and triglycerides assay kits were products of Randox Laboratories Ltd, (Antrim UK). All other chemicals and reagents were of analytical grade and of highest purity.

\subsection{Animals and Treatments}

\subsubsection{Animals}

In bred 5-6week-old male rats (Wistar strain) weighing 200 $\pm 20 \mathrm{~g}$ were used in this study. The rats were bred and housed in the animal house of the department of Chemical sciences, Ajayi Crowther University, Oyo, Nigeria. They were kept in wire meshed cages at room temp $\left(28-30^{\circ} \mathrm{C}\right)$ and under controlled light cycle $(12-\mathrm{hr}$ light: dark).They were fed with commercial rat chow (Ladokun feeds, Ibadan, Nigeria) and supplied water $a d$ libitum. All experiments were conducted without anaesthesia and protocol conforms to the guidelines of the National Institute of Health [22] for laboratory animal care and use. 


\subsubsection{Treatments}

Thirty healthy male albino rats (wistar strain) were randomly divided into three groups of 10 rats each. Group I (Control) received physiological saline, while groups II and III were administered the therapeutic and double therapeutic dose of dihydroartemisinin plus piperaquine phosphate (P-ALAXIN ${ }^{\circledR}$ ) respectively as presented in Table 1 . The treatments were administered in divided doses, twice daily for three days. The rats were sacrificed $24 \mathrm{hrs}$ after the last treatment.

Table 1: Experimental design

\begin{tabular}{lllll}
\hline EXPERIMENTAL GROUP & DAY 1 & DAY 2 & DAY 3 \\
\hline 1. CONTROL & $\begin{array}{l}\text { Physiological } \\
\text { saline }\end{array}$ & $\begin{array}{l}\text { Physiological } \\
\text { saline }\end{array}$ & $\begin{array}{l}\text { Physiological } \\
\text { saline }\end{array}$ \\
2. & THERAPEUTIC DOSE & $18 \mathrm{mg} / \mathrm{Kg} \mathrm{b.} \mathrm{w.}$ & $18 \mathrm{mg} / \mathrm{Kg} \mathrm{b.} \mathrm{w.}$ & 12g/ Kg b. w. \\
3. DOUBLE THERAPEUTIC DOSE & $36 \mathrm{mg} / \mathrm{Kg} \mathrm{b.} \mathrm{w.}$ & $36 \mathrm{mg} / \mathrm{Kg} \mathrm{b.} \mathrm{w.}$ & $24 \mathrm{mg} / \mathrm{Kg} \mathrm{b.} \mathrm{w.}$
\end{tabular}

b.w.= body weight

\subsection{Collection of blood samples for plasma preparation}

Blood was collected from the inferior vena cava of heart of the animals into heparinized tubes, and the rats were sacrificed by cervical dislocation. Plasma was prepared by centrifuging blood samples for ten minutes at $3000 \mathrm{x} g$ in an Eppendorf (UK) bench centrifuge. The clear supernatant was used for the estimation of plasma lipid profiles and enzymes.

\subsection{Preparation of cytosolic fractions}

The liver, excised from rat, blotted of blood stains, rinsed in $1.15 \% \mathrm{KCl}$ was homogenized in 4 volumes of ice-cold 0.01 M potassium phosphate buffer, ( $\mathrm{pH}$ 7.4). The homogenates were centrifuged at $12,500 \mathrm{~g}$ for 15 min at $4{ }^{\circ} \mathrm{C}$ and the supernatants, termed the post-mitochondrial fractions (PMF) were aliquoted and used for enzyme assays.

\subsection{Renal and liver functions test}

Plasma creatinine, urea and bilirubin determination was done using Sigma diagnostic kits. Methods for creatinine assays are based on colorimetric alkaline picrate methods [23] with Creatinine-picrate complex measured at $492 \mathrm{~nm}$. The urea determination method was based on the fearon reaction [24], with the Diazine chromogen formed absorbing strongly at 540nm. The dimethy sulphoxide method by [24] was used for bilirubin determination. The dimethyl sulphoxide form a coloured compound with maximum absorption at $550 \mathrm{~nm}$.

\subsection{Determination of plasma AST, ALT, ALP and GGT activities}

Plasma AST, ALT, ALP and GGT activities were determined using Randox diagnostic kits. Determination of AST and ALT activities were based on the principle described by Reltman and Frankel[25]. AST was measured by monitoring the concentration of oxaloacetate hydrazone formed with 2,4dinitrophenylhydrazine at $546 \mathrm{~nm}$ and ALT was measured by monitoring the concentration of pyruvate hydrazone formed with 2,4-dinitrophenylhydrazine at $546 \mathrm{~nm}$. ALP was determined in accordance with the principles of Tietz [26]. The p-nitrophenol formed by the hydrolysis of p-Nitrophenyl phosphate confers yellowish colour on the reaction mixture and its intensity can be monitored at $405 \mathrm{~nm}$ to give a measure of enzyme activity. GGT activity was measured based on a modification of the method described by Theodorsen et.al. [27] using Abbott diagnostic kit.

\subsection{Determination of plasma lipid profiles}

The plasma total cholesterol, HDL- cholesterol, LDL- cholesterol and triglycerides were determined using Randox diagnostic kits and the determination were based on CHOD-PAD enzymatic colorimetric method of Trinder [28].

\subsection{Assay of non-enzymatic antioxidants and lipid peroxidation}

Hepatic vitamin $\mathrm{C}$ was determined chemically according to the method of Erel et al. [29] using dinitro phenyl hydrazine (DNPH), while hepatic glutathione was determined according to the method of Jollow et al. [30]. The chromophoric product resulting from the reaction of Ellman's reagent with the reduced glutathione, 2nitro-5-thiobenzoic acid possesses a molar absorption at $412 \mathrm{~nm}$ which was read in a spectrophotometer. Reduced GSH is proportional to the absorbance at $412 \mathrm{~nm}$. The extent of lipid peroxidation (LPO) was 
estimated by the method of Vashney and Kale [31], the method involved the reaction between malondialdehyde (MDA; product of LPO) and thiobarbituric acid to yield a stable pink chromophore with maximum absorption at $532 \mathrm{~nm}$.

\subsection{Determination of antioxidant enzymes}

The procedure of Misra and Fridovich [32] as described by Magwere et al. [33] was used for the determination of hepatic superoxide dismutase (SOD) activity by measuring the inhibition of auto-oxidation of epinephrine at $\mathrm{pH} 10.2$ and $30^{\circ} \mathrm{C}$. Hepatic catalase activity was determined according to the method of Asru [34] by measuring the reduction of dichromate in acetic acid to chromic acetate at $570 \mathrm{~nm}$. Hepatic Glutathione S-transferase (GST) activity was determined by the method described by Habig et al. [35] using 1-chloro-2,4dinitrobenzene (CDNB) as substrate.

\subsection{Protein determination}

Protein determination of plasma and all fractions was estimated by the method of Lowry et al. [36] using bovine serum albumin as standard.

\subsection{Histopathological studies} studies.

The method of Baker and Silverton [37] was employed for the processing of liver for histopathological

\subsection{Statistical analysis}

Results were expressed as mean of 10 replicates \pm SD. Data obtained were subjected to one-way Analysis of Variance (ANOVA) and complemented with Student's t-test using StatPac ${ }^{\circledR}$ Statistical Software. Statement of statistical significance was based on $\mathrm{p}<0.05$.

\section{Results}

3.1 Effect of dihydroartemisinin- piperaquine phosphate on the levels of plasma Creatinine, Urea and Bilirubin in rats

There were significant increases $(\mathrm{P}<0.05)$ in the plasma Creatinine, Urea and Bilirubin levels of animals given the two doses of dihydroartemisinin- piperaquine phosphate (P-ALAXIN ${ }^{\circledR}$ ) when compared to the control (table 2). Specifically, the therapeutic and double therapeutic doses of P-ALAXIN ${ }^{\circledR}$ increased the plasma creatinine level by $67 \%$ and $117 \%$; plasma urea by $33 \%$ and $67 \%$; plasma Bilirubin by $85 \%$ and $119 \%$ respectively.

\subsection{Effect of dihydroartemisinin- piperaquine phosphate on the levels of plasma enzymes in rats}

Administration of dihydroartemisinin- piperaquine phosphate $\left(\mathrm{P}-\mathrm{ALAXIN}{ }^{\circledR}\right)$ significantly increased $(\mathrm{P}$ $<0.05$ ) plasma ALP, AST, ALT and GGT activities of the animals when compared to the control (table 3). Precisely, ALP activity was increased by $22 \%$ and $32 \%$ and ALT activity increased by $26 \%$ and $36 \%$ in both the therapeutic and double therapeutic dose treated groups respectively. Furthermore, AST activity was increased by $18 \%$ and $34 \%$ and GGT activity increased by $43 \%$ and $91 \%$ in the treated groups respectively.

\subsection{Effect of dihydroartemisinin- piperaquine phosphate on the levels of plasma lipid profiles in rats}

There were significant increases $(\mathrm{P}<0.05)$ in the plasma lipid profile levels of rats following the administration of two doses of dihydroartemisinin- piperaquine phosphate (P-ALAXIN $\left.{ }^{\circledR}\right)$ when compared to the control (table 4). Exactly, plasma total cholesterol was increased by $24 \%$ and $38 \%$; plasma HDL-cholesterol by $38 \%$ and $75 \%$; plasma LDL- cholesterol by $37 \%$ and $88 \%$ and plasma triglycerides by $28 \%$ and $64 \%$ in the therapeutic and double therapeutic dose groups respectively.

\subsection{Effect of dihydroartemisinin- piperaquine phosphate on the levels of hepatic antioxidant enzymes in rats}

The hepatic antioxidant enzymes, catalase (CAT) and superoxide dismutase (SOD) activities were significantly $(\mathrm{p}<0.05)$ reduced following treatment with two doses of dihydroartemisinin- piperaquine phosphate $\left(\mathrm{P}-\mathrm{ALAXIN}{ }^{\circledR}\right.$ ) when compared to the control (table 5). CAT and SOD activities were reduced in the treated groups by $26 \%$ and $71 \%$ and $18 \%$ and $94 \%$ respectively. Hepatic glutathione-S-transferase (GST) activity was also significantly reduced following treatment with therapeutic and double therapeutic doses of P-ALAXIN ${ }^{\circledR}$ by $25 \%$ and $76 \%$ respectively (fig. 4 ). 
3.5 Effect of dihydroartemisinin- piperaquine phosphate on the levels of hepatic non-enzymatic antioxidant and lipid peroxidation in rats

The hepatic level of non-enzymic antioxidants: ascorbic acid (Vit. C) and glutathione (GSH) were significantly $(\mathrm{p}<0.05)$ depleted following treatment with therapeutic and double therapeutic doses of dihydroartemisinin- piperaquine phosphate $\left(\mathrm{P}_{-} \mathrm{ALAXIN}^{\circledR}\right)$ when compared to the control: Vit C level was decreased by $45 \%$ and $131 \%$ (fig. 2) and GSH by $27 \%$ and $44 \%$ (fig. 3 ) in the treated group respectively. MDA level was significantly elevated $(\mathrm{p}<0.05)$ by $50 \%$ and $72 \%$ in the therapeutic and double therapeutic dose groups respectively compared to the control (fig. 5).

3.6 Effect of dihydroartemisinin- piperaquine phosphate on the histopathology of kidney and liver of rats Plates 1 and 2 are photomicrographs showing the effect of the therapeutic and double therapeutic doses of dihydroartemisinin plus piperaquine phosphate combination antimalarial on the liver and kidney respectively. The therapeutic dose of the drug resulted in hepatic portal congestion and cellular infiltration by mononuclear cells (Plate 1B). A severe hepatic portal congestion and cellular infiltration by mononuclear cells was observed in the double therapeutic dose group (Plate 1C). The therapeutic dose of the drug did not produce any visible lesion on kidney cells (Plate 2B), however, a severe renal cortical congestion was observed in the double therapeutic dose group (Plate 2C).

TABLE 2: Effect of dihydroartemisinin plus piperaquine phosphate (P-ALAXIN) ${ }^{\circledR}$ on plasma urea, creatinine, and bilirubin levels in rats.

\begin{tabular}{llll}
\hline TREATMENT & CREATININE $(\mathrm{mg} / \mathrm{dl})$ & UREA $(\mathrm{mg} / \mathrm{dl})$ & BILIRUBIN $(\mathrm{mg} / \mathrm{dl})$ \\
\hline Control & $0.13 \pm 0.01$ & $24.8 \pm 2.8$ & $0.36 \pm 0.02$ \\
Therapeutic dose & $0.22 \pm 0.01(67 \%)^{*}$ & $33.2 \pm 1.9(33 \%)^{*}$ & $0.67 \pm 0.02(85 \%)^{*}$ \\
Double therapeutic dose & $0.29 \pm 0.01(117 \%)^{*}$ & $41.6 \pm 1.7(67 \%)^{*}$ & $0.80 \pm 0.04(119 \%)^{*}$ \\
\hline
\end{tabular}

The values are the Means \pm SD (range) for ten rats in each group. *Significantly different from the control $(\mathrm{p}<0.05)$. Values in parenthesis represent $(\%)$ increase.

TABLE 3: Effect of dihydroartemisinin piperaquine phosphate (P-ALAXIN) ${ }^{\circledR}$ treatments on plasma Alkaline Phosphatase (ALP) and Alanine Aminotransferase (ALT), aspartate transaminase (AST) and gamma glutamyl transferase (GGT).

\begin{tabular}{lllll}
\hline TREATMENT & ALP (U/L) & ALT (U/L) & AST (U/L) & GGT(U/L) \\
\hline Control & $101.4 \pm 3$ & $61 \pm 1$ & $71 \pm 1.2$ & $7.4 \pm 1.1$ \\
Therapeutic dose & $123.6 \pm 3(22 \%)^{*}$ & $77 \pm 2(26 \%)^{*}$ & $83.8 \pm 2.6(18 \%)^{*}$ & $10.6 \pm 0.9(43 \%)^{*}$ \\
Double therapeutic dose & $134 \pm 4(32 \%)^{*}$ & $83 \pm 1.6(36 \%)^{*}$ & $95.2 \pm 2.6(34 \%)^{*}$ & $14.2 \pm 1.3(91 \%)^{*}$ \\
\hline
\end{tabular}

The values are the Means \pm SD (range) for ten rats in each group. ${ }^{*}$ Significantly different from the control, $(\mathrm{p}<0.05)$. Values in parenthesis represent $(\%)$ increase.

TABLE 4: Effect of dihydroartemisinin plus piperaquine phosphate (P-ALAXIN) ${ }^{\circledR}$ on plasma lipid profile in rats

\begin{tabular}{|c|c|c|c|c|}
\hline TREATMENT & $\begin{array}{l}\text { TOTAL } \\
\text { CHOLESTEROL } \\
(\mathrm{mg} / \mathrm{dl})\end{array}$ & $\begin{array}{l}\text { HDL- } \\
\text { CHOLESTEROL } \\
(\mathrm{mg} / \mathrm{dl})\end{array}$ & $\begin{array}{l}\text { LDL- } \\
\text { CHOLESTEROL } \\
(\mathrm{mg} / \mathrm{dl})\end{array}$ & $\begin{array}{l}\text { TRIGLYCER } \\
\text { IDES (mg/ dl) }\end{array}$ \\
\hline Control & $46.8 \pm 1.9$ & $23.6 \pm 2.1$ & $19.4 \pm 1.1$ & $28.2 \pm 2.3$ \\
\hline Therapeutic dose & $58 \pm 0.7(24 \%)^{*}$ & $32.6+2.8(38 \%)^{*}$ & $26.6 \pm 1.1(37 \%)^{*}$ & $36 \pm 1.2(28 \%)^{*}$ \\
\hline $\begin{array}{l}\text { Double therapeutic } \\
\text { dose }\end{array}$ & $64 \pm 1.7(38 \%)^{*}$ & $41.4 \pm 1.7(75 \%)^{*}$ & $36.4 \pm 2.2(88 \%)^{*}$ & $46.2 \pm 1.9(64 \%)^{*}$ \\
\hline
\end{tabular}

TABLE 5: Effect of dihydroartemisinin piperaquine phosphate (P-ALAXIN) ${ }^{\circledR}$ treatments on Hepatic Catalase Activities and Superoxide Dismutase (SOD) Activity in Rats.

\begin{tabular}{|c|c|c|}
\hline TREATMENT & $\begin{array}{ll}\mathrm{CAT} \quad(\mu \mathrm{mol} & \mathrm{H}_{2} \mathrm{O}_{2} \\
\text { consumed } / \mathrm{min})\end{array}$ & SOD (Units) \\
\hline & $0.33 \pm 0.02$ & $6.6 \pm 0.55$ \\
\hline Thera] & $0.24 \pm 0.01(26 \%)^{*}$ & $5.4 \pm 0.55(18 \%)^{*}$ \\
\hline Double therapeutic dose & $0.19 \pm 0.01(71 \%)^{*}$ & $3.4 \pm 0.55(94 \%) *$ \\
\hline
\end{tabular}

The values are the Means \pm SD (range) for ten rats in each group. $*$ Significantly different from the control, $\mathrm{p}<0.05$. Values in parenthesis represent $(\%)$ decrease 


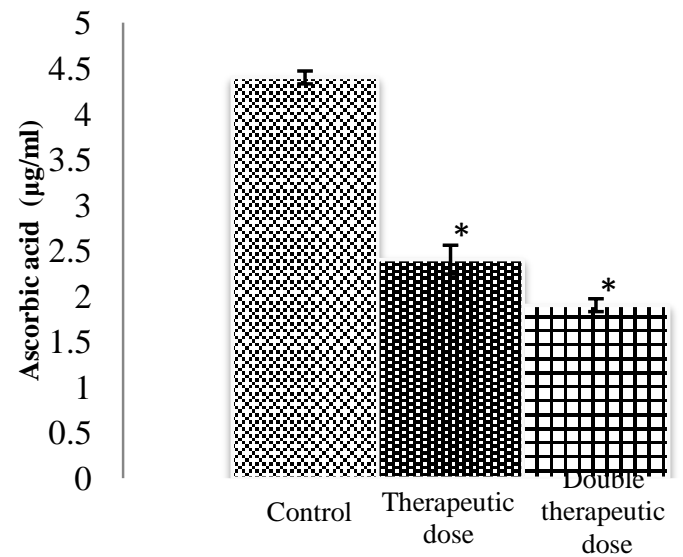

Figure 2: Effect of dihydroartemisinin piperaquine phosphate (P-ALAXIN) ${ }^{\circledR}$ treatments on hepatic Vitamin C concentration in Rats. The values are the Means \pm SD (range) for ten rats in each group. *significantly different from the control, $\mathrm{p}<0.05$

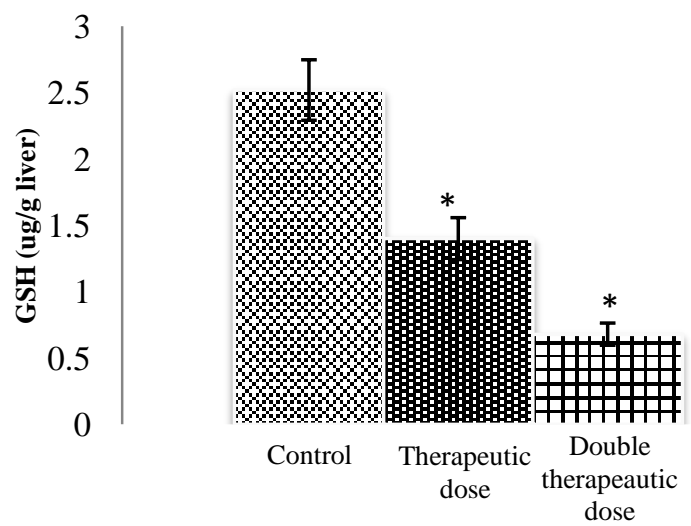

Figure 3: Effect of dihydroartemisinin piperaquine phosphate (P.ALAXIN $\left.{ }^{\circledR}\right)$ on Hepatic reduced Glutathione (GSH) level in Rats. The values are the Means \pm SD (range) for ten rats in each group. *significantly different from the control, $\mathrm{p}<0.05$.
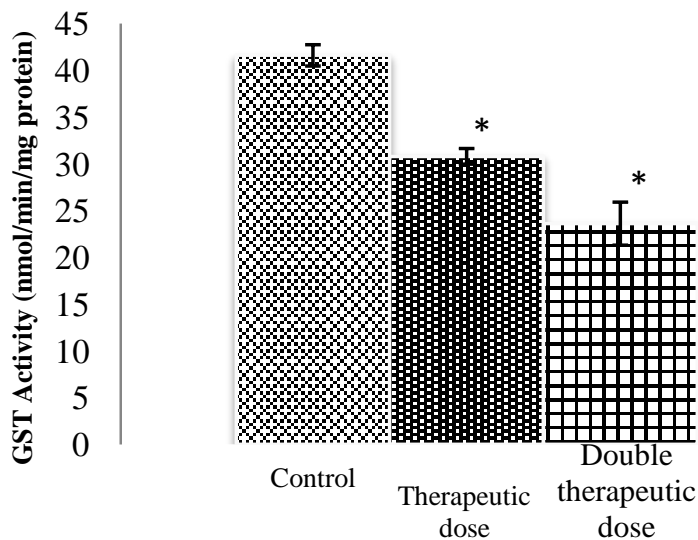

Figure 4: Effect of dihydroartemisinin plus piperaquine phosphate (P-ALAXIN $\left.{ }^{\circledR}\right)$ on Hepatic Glutathione-Stransferase (GST) activity in Rats. The values are the Means \pm SD (range) for ten rats in each group. *significantly different from the control, $\mathrm{p}<0.05$ 


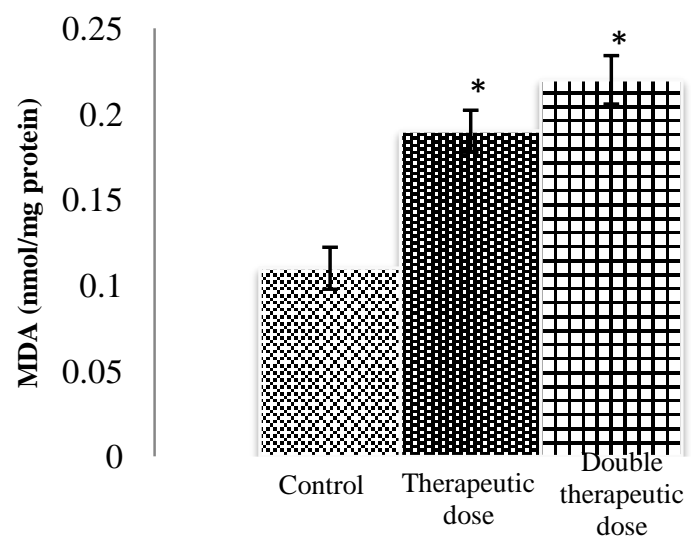

Figure 5: Effect of dihydroartemisinin plus piperaquine phosphate, $\left(\mathrm{P}-\mathrm{ALAXIN}{ }^{\circledR}\right.$ ) on Hepatic Lipid peroxidation (MDA) level in Rats. The values are the Means \pm SD (range) for ten rats in each group. *significantly different from the control, $\mathrm{p}<0.05$.

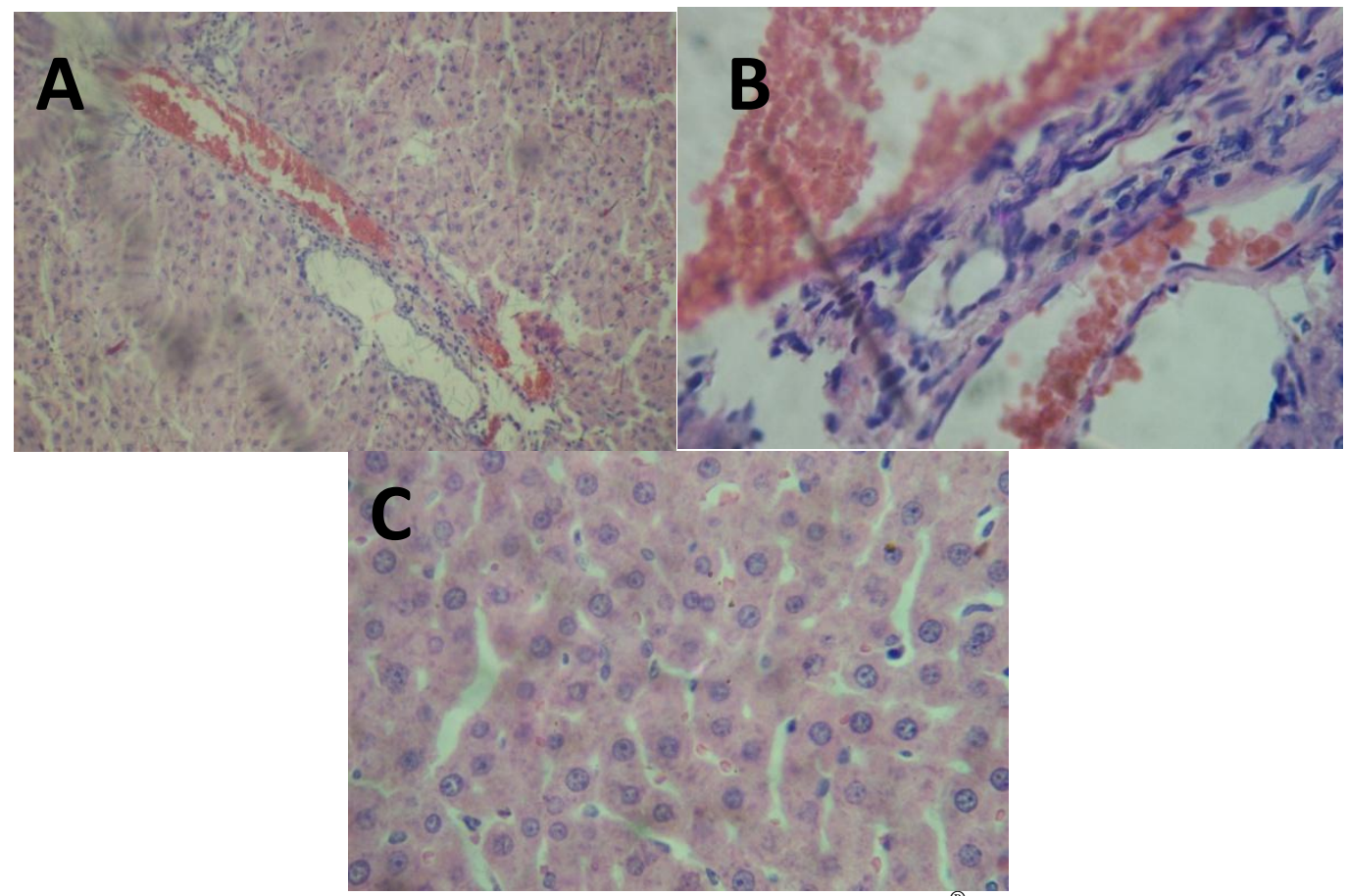

Plate 1: Photomicrographs of hepatocytes showing the effect of P-ALAXIN ${ }^{\circledR}$ :

$\mathrm{A}=$ Control: No visible lesions seen.

$\mathrm{B}=$ Therapeutic Dose: There is portal congestion and cellular infiltration by mononuclear cells

$\mathrm{C}=$ Double therapeutic dose: There is severe portal congestion and cellular infiltration by mononuclear cells

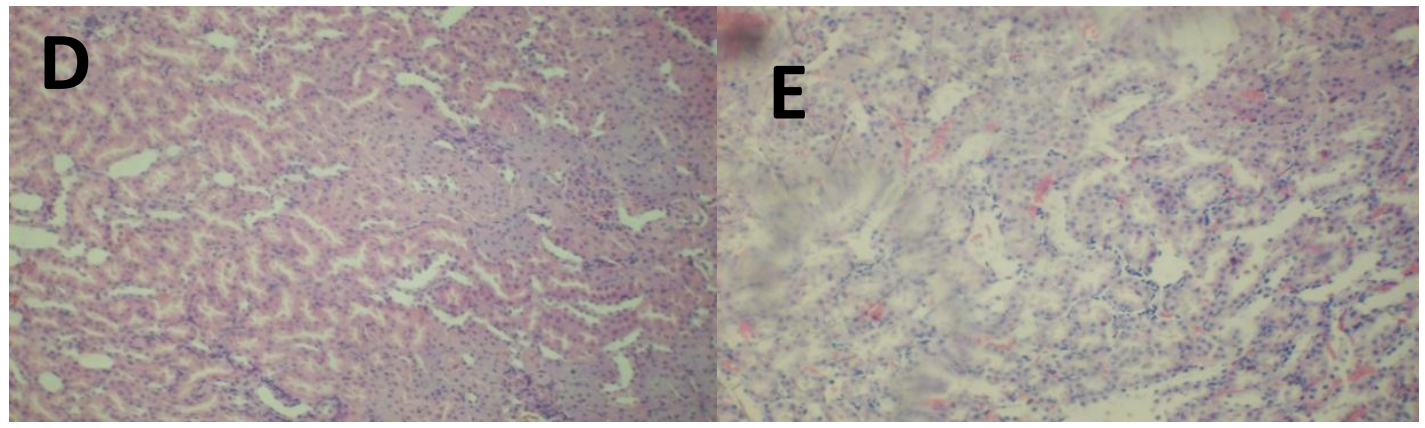




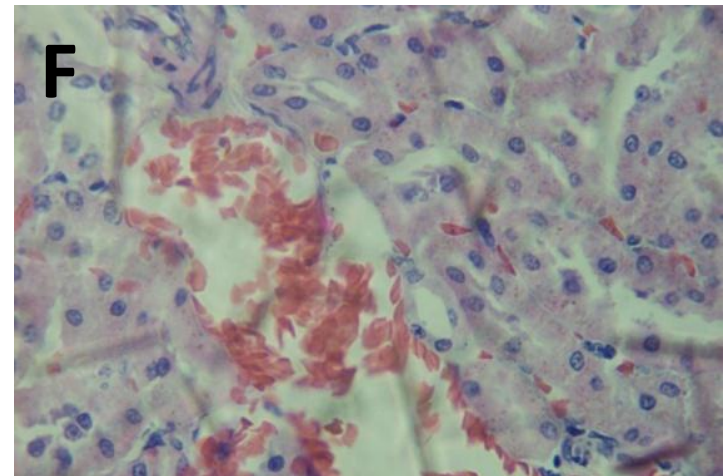

Plate 2: Photomicrographs of kidney cells showing the effect of P-ALAXIN ${ }^{\circledR}$ : $\mathrm{D}=$ Control: No visible lesions seen.

$\mathrm{E}=$ Therapeutic Dose: No visible lesions seen

$\mathrm{F}=$ Double therapeutic dose: There is severe renal cortical congestion.

\section{Discussion}

In the present study, the potential hepatic and renal toxicity as well as effect on antioxidant status of the therapeutic and double therapeutic doses of dihydroartemisinin and piperaquine phosphate (P-ALAXIN $\left.{ }^{\circledR}\right)$ was investigated in rats. Dihydroartemisinin (DHA) is a reduced product of artemisinin and it is the primary metabolite of artemisinin and its derivatives [38]. DHA is water soluble, relatively unstable and very prone to oxidative reactions because of the lactol moeity in its structure. Piperaquine is an antimalarial compound belonging to the 4-aminoquinolines. It is a highly lipophilic basic molecule [15]. The exact mechanism of action of piperaquine is unknown, but it is reasonable to assume that the compound has similar targets as chloroquine considering the close structural resemblance.

It is known that many organs show separate and unique responses to factors that regulate antioxidant and some marker enzymes [39]. Marker enzymes and other biochemical indices used in this study are important and effective tools in the diagnosis of diseases and toxicity arising from drug administration. Our results indicate that administration of dihydroartemisinin plus piperaquine phosphate induces marked renal and liver failure and affected both the enzymic and non-enzymic antioxidant system and lipid peroxidation.

Urea and creatinine are metabolic waste products that are freely filtered by the glomeruli of the kidneys [40] and their serum/plasma concentrations are commonly used to screen for renal or cardiovascular diseases [41, 42]. Elevation of the plasma levels of creatinine and urea is an indication of abnormal renal function [43]. Plasma urea has been reported to increase in acute and chronic intrinsic renal disease and also when there is decreased effective circulating blood volume with decreased renal perfusion [44, 45]. Creatinine have been implicated in kidney diseases such as acute glomerulonephritis, nephrosclerosis and tubular necrosis [46, 47]. Elevated plasma bilirubin has been associated with hepatocellular damage, intra and extra-hepatic biliary tract obstruction, and neonatal jaundice [48, 49]. The results, therefore, indicate that renal and hepatic function may be impaired in animals treated with therapeutic and double therapeutic dose of P-ALAXIN ${ }^{\circledR}$

The hepatocyte membrane distortion is associated with membranal leakage of the hepatocyte cytosolic contents which is manifested by significant elevation of the serum/plasma marker enzymes of acute hepatocellular damage namely ALT and AST, and ALP as a marker for hepatobiliary damage [50]. However, of these marker enzymes, ALT is the most reliable. AST is known to be present in abundance in the cardiac muscles, skeletal muscles, kidneys and testes, and ALP abundant in the growing bone. Thus, any disease state affecting any of these extrahepatic tissues significantly elevates the serum levels of these enzymes [51]. The elevated aminotransferases and phosphatases observed in the therapeutic and double therapeutic dose of PALAXIN $^{\circledR}$ treated animals is highly indicative of hepatic toxicity [52, 53]. These findings are in line with the findings of other researchers [17, 54, 55, 56, 57].Other antimalarial, such as chloroquine [58], amodiaquine [59], quinine [60] and halofantrine [61, 62] were also reported to elevate serum aminotansferases and phosphatases and may induce hepatic damage.

To prevent injury from reactive oxygen species (ROS), cells have developed defence systems. Besides scavenger molecules such as glutathione vitamin $\mathrm{C}$, or $\alpha$-tocopherol, specific enzymes, the antioxidants enzymes (AOE) fulfil this task. The expression of AOE can be regulated by oxidative stress itself $[63,64,6,65]$.Our data indicates that the therapeutic and double therapeutic dose of P-ALAXIN ${ }^{\circledR}$ affects both enzymatic and nonenzymatic antioxidants.The antioxidant enzymes Catalase and SOD are part of the primary intracellular antioxidants defence mechanism against oxidative stress [28].The decreased activities of SOD and CAT in the liver of the animals treated with the two doses of P ALAXIN ${ }^{\circledR}$ could be due to the organ's response to an 
increased production of reactive oxygen species, as a result of exposure to the drugs and their metabolites. The finding of decreased SOD and CAT activities in the liver of these animals as a result of drugs administration is not unexpected as both SOD and CAT are co-regulated in tissues in response to toxic assaults [66]. This result is consistent with the findings of other researchers [53, 67, 68].

Results from this study further reveals that treatment with therapeutic and double therapeutic dose of PALAXIN $^{\circledR}$ induced a significant decrease in hepatic glutathione-S-transferase (GST) activity, reduced glutathione (GSH) and vitamin C depletion. Glutathione-S-tranferase is a family of multifunctional isozymes found in all eukaryotes, catalysing both glutathione dependent conjugation and reduction reactions [67]. One main function of GST is to catalyse the biotransformation of xenobiotics, including drugs detoxification in the mercapturic acid pathway, leading to the elimination of toxic compounds [69] and also acting as an antioxidant enzyme [70]. In this study, GST activities were inhibited in animals treated with the two doses of the drug. This observation, therefore, suggests that this drug may alter the expression and activities of antioxidant enzymes as a result of toxic metabolites generated during their biotransformation. The level of reduced GSH and vitamin C is a measure of non-enzymic antioxidant and cellular redox status of cells in higher animals [71]. Studies have shown that the redox state of intracellular vitamin $C$ is controlled by the intracellular level of GSH [72]. Our results showed that administration of P-ALAXIN ${ }^{\circledR}$ decreased the overall redox status in the liver as indicated by a significant decrease in the level of GSH and Vitamin C. The observation on the decrease of GSH is in agreement with the findings of Bhattacharyya et al.[73], Ogunbayo et al. [74] and Adaramoye et al.[53] that observed significant decrease in GSH levels in the retina of rats, blood of rabbits and liver of rats respectively, following administration of chloroquine; artemether, coartem and halofantrine, while that of vitamin $\mathrm{C}$ is in consonance with the findings of Farombi et al.[75] that observed significant decrease in vitamin $\mathrm{C}$ in the blood of rats following treatment with chloroquine. The observed decrease in GSH levels and vitamin $\mathrm{C}$ further confirmed the formation of reactive oxygen species or toxic metabolites from the drug.

Our result also indicated an elevation in the levels of lipid profiles (plasma total cholesterol, HDL cholesterol, LDL-cholesterol and triglyceride), with a concomitant increase in the concentration of malondialdehyde (MDA) in the P-ALAXIN ${ }^{\circledast}$ treated groups. It has been suggested that cholesterol is a general indicator of the level of lipid in the circulation [76] and cholesterol and polyunsaturated fatty acids (PUFA) are the main components of LDL. PUFA is the substrate required for MDA formation and the amount of peroxidized lipid formed may be related both to the amount of substrate and to the level of lipid peroxidation (LPO). Therefore, the more the lipid, the greater the amount of lipid peroxidation activity and the greater the amount of lipid peroxidation products such as MDA. Increase in the level of lipid peroxidation has been described as a biomarker of tissue damage [77]. The thiobarbituric acid (TBA) assay is a suitable means of determining the extent of lipid peroxidation in tissues by measuring the concentration of MDA. The high level of lipid peroxidation following the administration of P-ALAXIN ${ }^{\circledR}$ in the liver may be attributed to the redox imbalance caused by the drug. Depletion of the membrane antioxidant system is known to result in the oxidation of membrane lipids leading to accumulation of lipid peroxides [77]. The accumulation of LPO products observed in this study is supported by the findings of Magwere et al. [32]. The concomitant decrease in the GSH level and vitamin C (a nonenzymic antioxidant) and enzymic antioxidant indices (SOD, CAT and GST activities) of the animals imply an increase susceptibility of the tissues to radical species generated by the drugs.

The histopathological observations in the liver of both the therapeutic and double therapeutic doses of P-ALAXIN ${ }^{\circledR}$-treated rats showed hepatic portal congestion and cellular infiltration by mononuclear cells and a severe hepatic portal congestion and cellular infiltration by mononuclear cells respectively. This could be due to the formation of highly reactive radicals because of oxidative threat caused by the drug. The accumulated hydroperoxides can cause cytotoxicity, which is associated with the peroxidation of membrane phospholipids. The therapeutic dose of the drug did not however, produce any visible lesion on kidney cells, but a severe renal cortical congestion was observed in the double therapeutic dose group. Based on the histology and other results in this study it can be seen that the administration of therapeutic and double therapeutic doses of P-ALAXIN ${ }^{\circledR}$ would have pronounced effect on the liver than the kidney. This may be due to the fact that the liver is the main site of drug metabolism, while the kidney is mainly involved in drug elimination.

\section{Conclusion}

In conclusion, our results suggests that the therapeutic as well as double therapeutic doses of PALAXIN ${ }^{\circledR}$ induced marked renal and hepatic failure and decreased the levels of antioxidant defence systems, with the effect more pronounced in the double therapeutic doses. As such caution should be taken in administering the drug beyond the therapeutic dose and the drug should be taken alongside with some antioxidants. 


\section{References}

[1] World Health Organization. Malaria Chemotherapy. Tech. Reg. Ser. Geneva, 1998.

[2] A. Djimdé, O.K. Doumbo, J.F. Cortese, K. Kayentao, S. Doumbo, Y. Diourté, A. Dicko, X.Z. Su, T. Nomura, D.A. Fidock, T.E. Wellems, C.V. Plowe, and D. Coulibaly, A molecular marker for chloroquine-resistant falciparum malaria. N. Engl. J. Med., 344,2001, 299-302.

[3] N.J. White, Antimalarial drug resistance and combination chemotherapy,Philos. Trans. R. Soc. Lond. B. Biol. Sci., 354, 1999, 739749.

[4] R.K. Haynes, Artemisinin and derivatives: The future for malaria treatment? Curr.Opin. Infect Dis., 14, 2001, 719-726.

[5] F. Nostenand N.J. White, Artemisinin-Based Combination Treatment of Falciparum Malaria,Am. J. Trop. Med. Hyg., 77,2007, 181192.

[6] R.N. Price, V.M. Van, F. Nosten, C. Luxemburger, A. Brockman, L. Phaipun, T. Chongsuphajaisiddhi and N.J. White, Artesunate versus artemether for the treatment of recrudescent multidrug-resistant falciparum malaria. Am. J. Trop. Med. Hyg., 59, 1998, 883888.

[7] H.M. McIntosh and P. Olliaro, Artemisinin derivatives for treating uncomplicated malaria. Cochrane Database System Review, CD000256(2)2000.

[8] N.J. White, Assessment of the pharmacodynamic properties of anti-malaria drugs in vivo. Antimicrob. Agents Chemother., 41, 1997, 1413- 1422.

[9] M.S. Mueller et al., "The Potential of Artemisia annua L. as a Locally-Produced Remedy for Malaria in the Tropics: Agricultural, Chemical and Clinical Aspects," J Ethnopharmacol, 73,2000, 487-493.

[10] N.J. White and P.L. Olliaro, Strategies for prevention of antimalarial drug resistance: rationale for combination therapy for malaria.Parasitol. Today, 12, 1996, 399-401.

[11] World Health Organization. Roll Back malaria Technical Consultation: Antimalarial drug combination therapy. WHO, Geneva:, WHO/CDS/RBM/2001, 35

[12] J.P. Song, S. Duong, S.Suou, T.Thou, S.Ses, Y.Sim, B .Tan and G.Q. Li, Clinical research of dihydroartemisinin-piperaquine with uncomplicated falciparum malaria. Natl Med J China83, 2003, 1099-1100.

[13] T.N. Trung, B .Tan, D .Van Phuc and J.P. Song, A randomized, controlled trial of artemisinin-piperaquine vs dihydroartemisininpiperaquine phosphate in treatment of falciparum malaria.Chin. J. Integr. Med.15, 2009, 189-192.

[14] T.M. Davies, T.Y. Hung, I.K. Sim, H.A. Karunajeewa and K.F. Ilett, Piperaquine: a resurgent antimalarial drug,65, $2005,75-87$.

[15] D.C. Warhurst,J.C. Craig, I.S. Adagu, R.K. Guy, P.B. Madrid and Q.L. Fivelman, Activity of piperaquine and other 4aminoquinoline antiplasmodial drugs against chloroquine sensitive and resistant blood-stages of Plasmodium falciparum Role of beta-haematin inhibition and drug concentration in vacuolar water- and lipid-phases. Biochem.Pharmacol. 73, 2007, $1910-1926$.

[16] C.R. Mann, K. Wilcock and S.S. Jick, The risk of severe depression, psychosis or panic attacks with prophylactic antimalarials.Drug Saf., 27, 2000, 203.

[17] H.U. Nwanjo,and G. Oze, Acute Hepatotocixity Following Administration Of Artesunate In Guinea Pigs. Internet J. Toxicol. 4, $2007,1-8$

[18] A.A. Ngokere, Ngokere, T.C and Ikwudinma, A.P. Acute study of Histo-morphological and Biochemical changes caused by Artesunate in Visceral Organs of the Rabbit, J. Exp. Clin. Anat., 3, 2004, 11- 16.

[19] S.R. Meshnick, Free radicals and antioxidants. Lancet, 344, 1994, 1441-1442.

[20] K.M. Robert, K.G. Daryl, A.M. Peter and W.R. Victor, in R.K. Murray et al. (Eds) Harper's Biochemistry 25(Appleton Lange, 2000), 169-170, 648-649.

[21] C. Karema, C.I. Fanello, C.vanOvermeir, J.P. van Geertruyden, W. van Doren, D. Ngamije and U. D'Alessandro, Safety and efficacy of dihydroartemisinin/piperaquine (DHP) for the treatment of uncomplicated Plasmodium falciparum malaria in Rwandan children. Trans. R. Soc. Trop. Med. Hyg.100, 2006, 1105-1011.

[22] Guide for the Care and Use of Laboratory Animals(Revised), NIH Publication No. 1985, 85-23.

[23] B. Jaffe, What made the radical break? N. Engl. J. Med., 286, 1972, 156

[24] N.W. Tietz, E.L. Pruden and O. Siggaard-Andersen, In C.A. Burtis, E.R. Ashwell (eds). Tietz textbook of Clinical Chemistry.(WB Saunders Company, London,1994) 1354-1374.

[25] S. Reltman, and S. Frankel, A colorimetric method for the determination of serum ALT and AST.Am. J. Clin. Pathol., 28, 1957, 5663.

[26] N. W. Tietz, Clinical guide to laboratory tests.3(W. B. Saunders Company, Philadelphia, 1995).

[27] L. Theodorsen, J.H. Strömme and M. Hørder, Scand. J. Clin. Lab. Invest., 36, 1976, 711-723.

[28] P. Trinder, Enzymatic colorimetric method of cholesterol determination,Ann. Clin. Biochem.6, $1969,24$.

[29] D. Erel, A. Kocyigit, S. Avci, N. Aktepe and V. Bulut, Oxidative stress and antioxidative status of plasma and erythrocytes in patients with malaria,Clin. Biochem., 30,1997, 631-639.

[30] D.J. Jollow, J.R. Mitchell, N. Zampaghone and J.R. Gillete, Bromobenzene induced liver necrosis: protective role of glutathione and evidence for 3,4-bromobenzene oxide as the hepatotoxic metabolite,Pharmacol., 11, 1974, 151-169.

[31] R. Varshney and R.K. Kale, Effect of calmodulin antagonist on radiation induced lipid peroxidation in microsomes,Int. J. Rad. Biol.,58, 1970, 733-743.

[32] H. Misra, and I. Fridovich, The role of superoxide anion in the autoauxidation of Epinephrine and a simple assay for superoxide dismutase,J. Biol. Chem.,247, 1972, 3170-3174.

[33] Magwere, T., Y.S. Naik and T.A. Hasler, 1997. Effects of chloroquine treatment on antioxidants enzymes in rats liver and kidney. Free Radical Biol. Med., 22: 321-327.

[34] K.S. Asru, Colorimetric assay of catalase. Anal.Biochem., 47, 1972, 389-394.

[35] W.A. Habig, M.J. Pabst and W.B. Jacoby, Glutathione transferases; the first enzymatic step in mercapturic acid formation,J. Biol. Chem., 249, 1974, 7130-7139.

[36] O.H. Lowry, N.J. Rosebrough, A.I. Farr and R.J. Randall, Protein measurement with folin phenol reagent,J. Biol. Chem., 193, 1951, $265-275$.

[37] F.J. Baker, and R.E. Silverton, Introduction to medical laboratory Technology 6(Butter worth, London, 1985).

[38] U.S. Svensson, M. Maki-jouppila, K.J. Hoffmann and M. Ashton, Characterization of the human liver in vitro metabolic pattern of artemisinin and auto-induction in the rat by use of nonlinear mixed effects modelling. Biopharmaceutics Drug Disposition, 24, 2003, 71-85.

[39] E.D. Harris, Regulation of antioxidant enzymes, FASEB J.,6, 1992, 2675-2683.

[40] F. Gaspari, N. Perico, M. Matalone, O. Signorini, N. Azzollini, M. Mister and G. Remuzzi, Precision of plasma clearance of iohexol for estimation of GFR in patients with renal disease,J. Am. Soc. Nephrol. 9, 1998, 310-313. 
[41] M. Ogawa, Present status and clinical therapy of pancreatic diseases,Nippon NaikaGakkaiZasshi, 10, 1992, $1899-1900$.

[42] J. Traynor, C.C. Geddes and J.G. Fox, How to measure renal function in clinical practice, BMJ, 333, $2006,733-737$.

[43] R. Mouton, and K. Holder, Laboratory tests of renal function,Anaesthesia intensive care medicine. 7, $2006,240-243$.

[44] J.S. Cameron, and R. Greger, Renal function and testing of function. In Davison A.M, Cameron J.S., Grunfeld J.P., Kerr D.N.S., Rits E., Winearl G.C. (Eds.) Oxford textbook of Clinical Nephrology, (Oxford, London, 1998)36-39.

[45] S.R. Orth, and E. Ritz, The nephritic syndrome,New Eng. J. Med., 338, 1998, 1202-1211.

[46] M. Ogeturk, I. Kus, N. Colakoglu, I. Zararsiz, N. Ilhan, M. Sarsilmaz, Caffeic acid phenethyl ester protects kidneys against carbon tetrachloride toxicity in rats, J. Ethnopharmacol.,97, 2005, 273-280.

[47] L. Pari,and P. Murugan, Tetrahydrocurcumin: effect on chloroquinemediated oxidative damage in rat kidney. Basic Clin.Pharmacol.Toxicol.,99, 2006, 329-334.

[48] E.L. Renner, Liver function test. Ballieres Clinical Gastroenterology, 9,1995, 661-772.

[49] J.M. Tredger, and K.A. Sherwood, The liver: New functional, prognostic and diagnostic tests,Annals of Clinical Biochemistry, 34, 1997, 121-141.

[50] D. Bhattacharyya, R. Mukherjee, S. Pandit, N. Das and T.K. Sur, Prevention of carbon tetrachloride induced hepatotoxicity in rats by Himoliv ${ }^{\circledR}$, a polyherbal formulation,Ind. J. Pharmacol., 35, 2003, 183-185.

[51] L.S. Friedman, P. Martin and S.J. Muòoz, Liver function tests and the objective evaluation of the patient with liver disease. In: Hepatology:A Textbook of Liver Disease. 3 (Philadelphia: WB Saunders Co., 1996), 791-833.

[52] N.H. Vahdati-Mashhadian, and A.O. Rakhshandeh, An investigation on LD50 and subacute hepatic toxicity of Nigella sativa seed extracts in mice, Pharmazie, 60, 2005, 544-547.

[53] M.C. Ewaraiah, and T. Satyanarayana, Hepatoprotective activity of extracts from stem of Mussaenda erythrophylla Lam. Against carbon tetrachloride-induced toxicity in rats,JPRHC, 2, 2010, 23-31.

[54] O.A. Adaramoye, D.O. Osaimoje, A.M. Akinsanya, C.M. Nneji, M.A. Fafunso and O.G. Ademowo, Changes in antioxidant status and biochemical indices after acute administration of Artemether, Artemether-Lumefantrine and Halofantrine in rats, Basic Clin. Pharmacol.\&Toxicol., 102, 2008, 412-418.

[55] A. Udobre, E.J. Edoho, O. Eseyin and E.I. Etim, Efeect of artemisinin with folic acid on the activities of aspartate aminotransferase, alanine amino transferasenand alkaline phosphate in rat,Asian J. Biochem., 4, 2009, 55-59.

[56] G.N. Anyasor, and O.T. Odunsanya, Coartemether in Dietary Oil Induces Oxidative Stress and Hepatotoxicity in Albino Rat,Researcher, 3, 2011, 35-41.

[57] A.W. Obianime, and J.S. Aprioku, Mechanism of action of Artemisinin on Biochemical, Hematological and Reproductive parameters in Male Guinea-Pigs,Int. J. Pharmacol. 7, 2011, 84-95.

[58] Pari, L. and R.D. Amali, Protective role of tetrahydrocurcumin (THC) an active principle of turmeric on chloroquine induced hepatoxicity in rats. J. Pharm. Pharm. Sci., 8, 2005, 115-123.

[59] E.O. Farombi, B.I. Olowu and G.O. Emerole, Effect of three structurally related antimalarial drugs on liver microsomal components and lipid peroxidation in rats. Comp. Biochem. Physiol., 126, 2000, 217- 224.

[60] K.F. Debra, and N.L. Megan, Quinine-induced hepatotoxicity. Ann. Pharmacother., 33, 1999, $32-34$.

[61] M.P. Vincent, J.P. Becquart, M.C. Receveur, O. Nordor and M. Le-Bras, Halofantrineoverdosage. Presse Med., 21, $1992,131$.

[62] E. Obi, O.E. Orisakwe, L.A. Asomugha, O.O. Udemezue and V.N. Orish, The hepatotoxic effect of halofantrine in guinea pigs.Indian J. Pharmacol. 26, 2004, 303-305.

[63] S. Shull, N.H. Heiintz, M. Periasamy, M. Manohar, Y.M.W. Janssen, J.P. Marsh, B.T. Mossman, 1991. Differential regulation of antioxidants enzymes in response to oxidants. J. Biol. Chem., 266:24398-24403.

[64] D.J. Tate, M.V. Micelli and D.A. Newsome, Phagocytosis and $\mathrm{H}_{2} \mathrm{O}_{2}$ induced catalase and metallothionein gene expression in human retinal pigment epithelial cells. Investig. Ophthamol. Vis. Sci., 36, 1995, 1271-1279.

[65] G. Schmuck, Haynes, R.K., Establishment of an in vitro screening model for neurodegeneration induced by antimalaria drugs of Artemisinin-type. Neurotoxicity Res. 2, 2000, 37-49.

[66] H. Lew, and A. Quintanilha, Effects of endurance training and exercise on tissue anti-oxidative capacity and acetaminophen detoxification.Eur. J. Drug Metab.Pharmacokinet., 16, 1991, 59-68.

[67] A.W. Obianime, and J. S. Aprioku, Comparative study of artesunate, ACTs and theircombinants on the biochemical parameters of male guinea-pigs.Afr. J. Biotech. 8,2009, 5059-5065.

[68] R.B. Rajurkar, Z.H. Khan and G.T. Gujar, Studies on levels of Glutathione S-Transferase, its Isolation and Purification from Helicoverpa armingera,Curr. Sci., 85, 2003, 1355-1360.

[69] J.D. Hayes, and D.J. Pulford, The glutathione S-transferase supergene family: regulation of GST and the contribution of the isoenzymes to cancer chemoprotection and drug resistance, Crit. Crit. Rev. Biochem. Mol. Biol.,30, 1995, 445-600.

[70] O.A. Adaramoye and E.O. Adeyemi, Hepatoprotection of D-galactosamine-induced toxicity in mice by purified fractions from Garcinia kola seeds,Basic ClinPharmacolToxicol., 98, 2006, 135-141.

[71] B. Chance, H. Sies and A. Boveris, Hydroperoxide metabolism in mammalian organs.Physiol. Rev., 59, 1979, 527-605.

[72] R. Stocker, M.J. Weidemann and N.H. Hunt, Possible mechanisms responsible for the increased ascorbic content of plasmodium vinkei-infected mouse erythrocytes.BiochimicaActa, 881, 1986, 391-397.

[73] B. Bhattacharyya, T.K. Chatterjee and J.J. Ghosh, Effects of chloroquine on lysosomal enzymes, NADPH-induced lipid peroxidation, and antioxidant enzymes of rat retina. Biochem.Pharmacol., 32, 1983, 2965-2968.

[74] O.A. Ogunbayo, R.A. Adisa, O.G. Ademowo and O.O. Olorunsogo, Incidence of chloroquine induced oxidative stress in the blood of rabbit. Int. J. Pharmacol. 2, 2006, 121-125.

[75] E.O. Farombi, Y.Y. Shyntum and G.O. Emerole, Influence of Chloroquine Treatment and Plasmodium falciparum Malarial Infection on some enzymatic and non-enzymatic antioxidant defence indices in humans. Drug and ChemicalToxicol., 26, 2003, 5971.

[76] D.F.I.Thurnham, R. Singkamani, R. Kaewichit, K. Wongworapat, Influence of malarial infection on peroxyl-radical trapping capacity in plasma from rural and urban Thai adults. Brit. J.Nut., 64, 1990, 257-271.

[77] J.M.C.Gutteridge, Lipid peroxidation and antioxidants as biomarkers of tissue damage,Clin. Chem.,41, 1995, 1819 - 1828. 